\title{
Study on the Women's Position in Yang Jiang's Literary Works
}

\author{
Feng Wang \\ Department of Arts and Sciences Jilin Agricultural Science and Technology College, Jilin, Jilin 132101
}

\begin{abstract}
Keywords: Yang Jiang Literary Works; Women Position; Society Effect
\end{abstract}
\begin{abstract}
In Mr. Yang's novels, there are active women who have a distinct personality and dare to love and hate but inadvertently intervene in other people's marriages or couples. In the contradiction between emotion and morality, ideal and reality, their pursuit of love sparks the women's awakening, but also reveals the tragic color that emotional entanglement brings to their destiny. On these women's third parties, Mr. Yang was entrusted with thinking about the emotional fate of women. The interpretation of Yang Jiang's novel texts analyzes the images of female third parties, combined with the author's own life experiences, and Mr. Yang Xi's tentative exploration of "females" and personality, emotions and morality, and women's destiny and outlets can be seen.
\end{abstract}

\section{Introduction}

Yang Jiang is a multi-faceted player. The script, novels, literary theory, prose, and translations all have fun and are highly praised by readers. However, from the evaluation of discourse system, especially from the perspective of literary history, Yang Hao is lonely. Literary history before the 1980s (e.g., Ding Yizhuo, “A Brief History of Modern Chinese Literature”, published by the Writer Publishing House in 1955, and the 1962 Writing Team of the History of Chinese Modern Literature, Department of Chinese Studies, Jilin University. "Chinese Modern Literature History" did not mention Yang Hao. The rewriting of literary history in the 1980s and the literary history published before the 1990s still do not mention Yang Hao. At the turn of the century, Yang Jiangcai began to occupy a place in the group of senior prose writing (eg, Liu Xiqing's "A Brief History of New China Literature" published by Beijing Normal University in 1996 and Hong Zicheng published by Peking University Press in 1999. "The History of Contemporary Chinese Literature" and Zhu Donglin, Ding Fan, and Zhu Xiaojin, “The History of Modern Chinese Literature (1917-1997)”, published by the Higher Education Press in 1999. In the 21st century, Yang Although research has gradually increased, literary history has gradually increased its assessment. For example, Ling Yu affirmed Yang Shu's satire in the forties of the 40's comedy on civic culture, and Liu Yong explored the unique charm of Yang's essay "Transcendence on the worldly life”, German sinology Gu Bin said that "Translator Yang Jiang” wrote the prose "Language is unobtrusive and has no regrets." In addition, some scholars have done special research on her novels, essays, or dramas, such as Yang Yi, Min Ze, and Zhang. Jian et al.. On the whole, the comprehensive study of Yang Jiang's creation has not been fully carried out, and it lacks overall observation and comprehensive sorting, mostly local reviews and research. Before this, only Kong Qingmao's "Yang Xi's Biography” (Huaxia Publishing House, 1998) and Luo Yinsheng’s "Yang Yu Biography” (Cultural Art Publishing House, 2005) are relatively comprehensive. These conditions fully illustrate the contemporary literary world. Yang Cong's literary contributions have been of concern, but she still fails to give her full and complete appraisal.

\section{Category of female images in Yang Jiang's literary works}

Romantic passionate type. One of the important spiritual achievements of the "May 4th" New Culture Movement is "human discoveries" and "female discoveries." [2] (P45) Romantic and passionate women in pursuit of freedom of marriage have emerged in this age of enlightenment. This type of women is generally dominated by female students. Yang Hao successfully created such images in his early novels. The lead actress in "Oh, no!” [3] (P3) is a romantic and passionate seed. 
She has two friends, Tang Yu and Xiao Wang. In order to prevent the two boyfriends from being jealous, "I also pay attention to separating them: I will play with Tang Wei at the end of the week, and I will play with Xiao Wang at the end of the next week.” In order to make a decision between two people, she "feels like she likes soup more." However, Tang Tang has a bad temper and a poor family. He may not be an official in his life. Xiao Wang is a political student. His father is a big official. He has money in his family and he has a good temper. He thinks he is sincere, and according to the fortune telling, Yi is the official wife's life, but Xiaowang's biggest drawback is his short stature. In fact, the choice between $\mathrm{Bi}$ and Wang is to choose between romance and reality. The mother reminded her not to be fazed by a man and to be suffocated in the future. He descended from the romantic cloud and chose reality. He felt that he and the king would be comfortable in the future. After failing at the end of the game, Miao got a quick letter from the American college. His development is more realistic than romantic love. She is happy to be "heart-beat" and "smiley."

Good wife and mother type. Wife and mother are historical concepts. In the early 20th century, women's discourse was introduced from Japan. Unlike the feudal society, "women have no talent is a virtue." Virtuous wives and mothers are certain independent "personalities", have certain knowledge and ability, but must also be good at managing family affairs and conform to the Confucian values of women. [1] Yang Jiang's novels have created a group of women who are good-natured and well-to-be mothers. They are either sexually attractive and sardonic. They have a dignified appearance; In the "Little Spring", Suifen is a virtuous and kind person who quietly assumes all the housework, and serves her husband and two sons. She is hard-working and frugal. When she discovers her husband's extramarital affairs, she angers and runs away from home and lingers. She wanted to treat herself well. As a result, she was still reluctant to spend money. "Only calling for a bowl of noodles", even Yu Bin did not admit that "Lian Fen is a good wife and a good wife of first class".

Work in mind type. Zhao Xinyu in Besieged City said: "I think women are all scheming."[4] Women who work on their own minds are also one of the female images that Yang $\mathrm{Xi}$ is good at depicting and portraying. Such images are mainly concentrated in Joke "Bathing" in two novels. In the Big Jokes, the intellectuals in Wen Jia Yuan lived well. A group of intellectuals headed by Julie and Zhou Yiqun have lived a life of pampering. Zhu Li is the wife of the deputy director Cai Yong, who is beautiful and beautiful and treats people lightly. Zhou Yiqun, the wife of the legal scholar Lin Ziyu, was considered "fresh and beautiful" when she was young. Now she "was fat, like a blooming rose". The two people have a common lover, Zhao Shouheng. Zhao Shouheng was originally in love with Zhou Yiqun and is now empathetic with Julie. The two ladies are therefore jealous and brazen. Two years after the death of Dr. Wang Shijun, a member of the Society, his wife Chen Qian came to Wen Jiayuan to process her husband's belongings. In fact, Chen Qian was deceived by Zhou Yiqun to Wen Jiayuan. Zhou Yiqun wanted to introduce Chen Qian to Zhao Shouheng and wanted to use Chen Qian's beauty to suppress Julie.

Of course, several types can not completely summarize the female images of Yang Jiang in the novel, which in turn proves the richness and superb creative skills of Yang Jiang's novels. Yang Xiao's creations were concentrated in the third and fourth decades of the 20th century and the seventies and eighties. In the previous period, “class emancipation and resistance to Japan's national salvation" became the "mainstream discourse of all things" [2]; in the latter period, "root-seeking literature" occupied the mainstream, and "avant-garde fiction" was in the ascendant. Regardless of whether it is content or style, Yang Jiang's creation is always in the marginalized position. It is exactly this kind of marginalization of creation, but she gives her a clear perspective and gives her work wisdom. As Austin said in the "Norsangjue Temple," "the novelist displays the highest wisdom in his works; he uses the most appropriate language to convey to the world his most thorough understanding of mankind." Yang Using a language full of wisdom, she created different female images and created a broad space for thinking for readers. 


\section{Exploration of women's status and emotional outlets}

The novels of Mr. Yang Jiang not only reflect the problems mentioned above, but also explore the fate and way out of women. Among the many women in the novel, whether full-time wife or unmarried girl, they face a problem: How to keep themselves in love, but not to lose direction when there is a gap in love. This is also a problem faced by women for thousands of years. It can be said that the development of human society is at the expense of women gradually exiting the political stage. In the transition and development of the matriarchal society to the patriarchal society, women gradually faded out of the center of power and retreated to the housewife position with the family as the center of gravity. For a long time, women have been regarded as men's accessories. With the ultimate goal of "good wife and good mother", they have assumed the responsibility of inheriting and supporting their children. Under such a concept, women themselves are also demanding family and husband. As the center, ignoring their own needs and contact with the outside world, waiting until the children grow up, do not need them to take care of the family at all times, just like Mrs. Yu in "Little Spring" finds "what is a good wife? The site went? She had to take up the site and stir herself in the middle of the oil and salt. Her husband's world, she couldn't walk in. The world of the child, she couldn't walk in. When she was left, she became cumbersome." What's wrong? "Maybe it was her own, woman herself". The woman's life was imprisoned in the family's cage. The individual's value was completely relegated to the role of her daughter, wife, and mother. She did not live her own life. The collapse of the feudal system, the establishment of a new system, and the establishment of a civilized society urgently demanded the advancement of women. Therefore, the equality of men and women in the system came into being, and brought about the opportunity for the liberation of women. Marriage autonomy, monogamy The protection of the emotional fate of the majority of women. However, institutional equality is only a social condition for emancipation, and true emancipation requires women to break free from the shackles of tradition, to become an independent person, to have freedom of thought and to be a person's "personality", and to realize human values. The rise of the May 4th Movement awakened some women and enabled them to walk out of their homes and seek self-worth. But where do you go after you wake up? The women who have lost their way gradually become depressed and return to the roles of family, wife, and mother. This is not a complete sober, incomplete liberation. On the one hand, they want to be respected like men and have the right to speak like men. On the other hand, they also want men's approval and live in the image that men want and appreciate. This makes them return to men's in the shadow. In the face of the problems that many women have inevitably concerning the family and the self, Mr. Yang Xi's concept is, in Mr. Hu Shi's words, "self-reliance on the concept of life of a good wife and mother". "The meaning of 'self-reliance' is only to develop individual talents, not to rely on others, to live independently, and to be able to work for the society" [5]. She loves her husband and loves her daughter but also loves literature. She can wield the sweat in front of the kitchen and can also paint before the case. She finds a balance between personality and women, takes care of the family, cares for her husband and cares for her children, but does not give up her hobbies and careers. Pursuing this is the answer given by Mr. Yang Jiang in terms of the status and emotional outlet of women.

\section{Conclusion}

In her novels, Mr. Yang Jiang has created a series of female images with different attitudes and human nature. These images shine brightly in the history of modern and contemporary literature. The reason is that Yang Jiang occupies a clear perspective in his creation and presents his unique wisdom and thinking in his works. Understanding the different types of female images in Yang Jiang's novels can fully understand Yang's understanding of society and the rich connotation of her novels. 


\section{Acknowledgements}

Jilin Province Department of Education "13th Five-Year" Science and Technology Research Project

No.: JJKH20170356SK

\section{References}

[1] Yang Hao. Yang Hao's Portfolio: Volume 1 [M]. Beijing: China Social Sciences Press, 1993.

[2] Shi Jinxiu, Liu Jiao. The narrative ethics re-understanding: adhere to social morality [J]. Journal of Hunan University of Technology (Social Science Edition) ,2014(4): 66 - 69.

[3] Shi Yongxiu. On the female images in Yang Jiang's novel "Bathing" [J]. Jiangxi Social Sciences, 2003(2): 90-93.

[4] Yang Hao. Yang Hao's Portfolio: Volume 2 [M]. Beijing: China Social Sciences Press, 1993: 60.

[5] Xu Hao. Great Wisdom and Small Text: On Yang Xiao's Theory of Art [J]. Literary Theory Research, 2002(1):70. 